\title{
Evolución de la transmisión vertical de la infección por virus de inmunodeficiencia humana en Chile
}

\author{
Ana Chávez P., Ana M. Álvarez P., Elba Wu H., Anamaría Peña D., Eloísa Vizueta R. y \\ Comité Nacional de SIDA Pediátrico, Sociedad Chilena de Pediatría
}

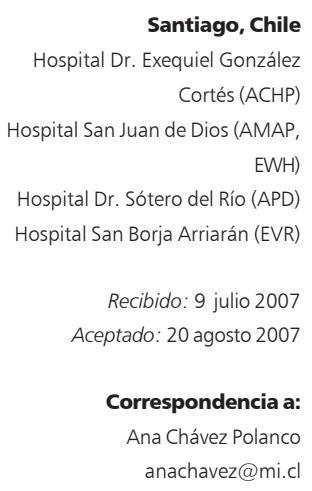

anachavez@mi.cl

\section{Changes in vertically transmitted human immunodeficiency virus infection Chile}

The identification of various risk factors of vertical human immunodeficiency virus (HIV) transmission resulted in the development of strategies whose aim was to decrease the mother's viral load, to reduce her child's exposure to it during delivery, and to avoid the subsequent viral exposure due to breastfeeding. The administration of antiretroviral treatment during pregnancy, delivery and to the neonate (PACTG 076) proved to be useful. At a first stage, zidovudine was used. A triple combination therapy was then administered. Initially, the viral transmission in mothers who were enrolled in protocols for vertically transmitted HIV prophylaxis was reduced to $9.5 \%$, whereas the last measurement carried out between 1998 and 2005, the initial figure was brought down to $2 \%$. Nevertheless, the delivery of infected children whose mother's HIV status was unknown is still considered likely to happen. The main step to be taken to reduce HIV infection among children is to perform universal HIV tests during pregnancy, so that HIV positive pregnant patients conveniently receive proper prophylaxis. We look forward to achieving this by following the new prevention guidelines of vertically-transmitted HIV infection, developed by the Comisión Nacional del SIDA of the Chilean Health Ministry.

Key words: human immunodeficiency virus, vertical transmission, prophylaxis.

Palabras claves: virus de inmunodeficiencia humana, transmisión vertical, prevención.
$\mathrm{E}$ 1 primer caso de infección por virus de la inmunodeficiencia humana (VIH) en un niño, en el país, se diagnosticó el año 1987. Se trató de un paciente que había sido multitransfundido unos años antes, a raíz de un grave accidente, desarrollando, a posteriori, un síndrome de inmunodeficiencia adquirida (SIDA).

En 1989, se diagnosticaron los primeros casos de infección por VIH adquirida en forma vertical madrehijo, mecanismo de transmisión que es responsable de más de $90 \%$ de los casos pediátricos de esta infección. Desde esa fecha hasta el año 1994, se había pesquisado en el país 161 hijos de madre infectadas con VIH, comprobándose infección por este virus en 57 de ellos, lo que permitía estimar la tasa de transmisión por esta vía, en alrededor de $35,4 \%$, a pesar de no conocerse el total de niños en esta situación ${ }^{1,2}$.

Los avances en el conocimiento de esta nueva enfermedad permitieron establecer diversos factores que inciden en el riesgo de la transmisión vertical (TV), unos relacionados con el estado de la infección de la madre, otros con el embarazo y parto y otros con el hijo.

- Entre los factores relacionados con el estado de la infección de la madre, representan un mayor riesgo de transmisión una carga viral alta $(>1.000$ copias $\mathrm{ARN} / \mathrm{ml}$ ), recuentos absolutos de linfocitos CD4 bajos, la presencia de enfermedades constitutivas de SIDA, la de infecciones génito-urinarias durante el embarazo y la coexistencia con otras infecciones de transmisión sexual.

- En relación con el parto, constituye un mayor riesgo su resolución por vía vaginal, comparada con la cesárea realizada antes del inicio del trabajo de parto, excepto en aquellas mujeres embarazadas que llegan al parto con carga viral (CV) no detectable, en las que esta vía no representaría beneficio. También representa un mayor riesgo la rotura de membranas con más de cuatro horas de anticipación al parto.

- En relación con el niño, los procedimientos invasores de monitoreo fetal, el parto prematuro y la lactancia materna, constituyen factores para un mayor riesgo de transmisión ${ }^{3-5}$.

De acuerdo con lo anterior, se diseñaron estrategias dirigidas a reducir la CV en la mujer gestante, disminuir la exposición del niño al VIH durante el parto y eliminar la exposición al VIH a través de la leche materna. 
De esta manera, las recomendaciones actuales para la atención de la mujer embarazada con infección por VIH, incluyen el control estricto durante la gestación con los siguientes objetivos:

- pesquisar y tratar precoz y oportunamente, infecciones durante este período.

- resolver el parto mediante cesárea electiva a las 38 semanas de gestación, con membranas intactas.

- administrar terapia anti-retroviral (TARV) durante el embarazo y el parto, con el objeto de reducir la CV en la madre (medida con el máximo impacto).

Como acciones complementarias, el neonato debe recibir TARV antes de 6 horas de nacer, terapia que debe mantenerse durante las primeras seis semanas de vida. Además, no recibirá lactancia natural, debiendo ser alimentado con leche artificial ${ }^{3,4,6-8}$.

En 1994, se conocieron los resultados del protocolo PACTG 076, estudio del Pediatric AIDS Clinical Trial Group de E.U.A. y Francia, que demostró que la administración de zidovudina (ZDV) a la madre durante el embarazo y parto y al recién nacido $(\mathrm{RN})$ durante las primeras semanas de vida, disminuía el riesgo de TV del VIH en alrededor de $70 \%$, en mujeres que cumplían estrictos criterios de inclusión: tener entre 14 y 34 semanas de gestación al comenzar la terapia, enfermedad en etapa inicial con recuento de CD4 $\geq 200 / \mathrm{mm}^{3}$, no haber recibido TARV durante el embarazo y no tener indicación para ésta. Este protocolo incluía la administración de ZDV desde las 14-34 semanas de gestación durante todo el embarazo, seguido por su infusión i.v. durante el parto y administración oral de ZDV al RN durante seis semanas ${ }^{1,4,9}$.

En nuestro país se inició la utilización de dicho protocolo a fines de ese año, con su aplicación en algunas mujeres embarazadas en que se pesquisó esta infección ${ }^{1}$.

Tabla 1. Prevención de la transmisión vertical del VIH en Chile. Binomios madre-hijo en PPTV*

\begin{tabular}{lc|} 
Año & n en protocolos \\
1998 & 37 \\
1999 & 35 \\
2000 & 43 \\
2001 & 54 \\
2002 & 62 \\
2003 & 61 \\
2004 & 74 \\
2005 (a julio 31) & 35 \\
Total & 401 \\
\hline
\end{tabular}

\footnotetext{
* Protocolo para la prevención de la transmisión vertical
}

Una primera evaluación de este protocolo, que incluyó a 63 mujeres cuyos hijos nacieron entre 1995 y 1997, reveló que sólo seis de ellos nacieron infectados con VIH, lo que demostró una importante reducción de la TV a 9,5\%, en ese grupo.

A partir de 1998, se incorporó a todas las mujeres gestantes en que se pesquisó infección por VIH a distintos protocolos de prevención de TV (PPTV) con uso de TARV, inicialmente ZDV, de acuerdo con el PACTG $076 \mathrm{y}$, posteriormente, con tres fármacos (triterapia), con el objeto de lograr CV indetectables en el momento del parto, manteniendo las recomendaciones de manejo del embarazo, parto y el RN, medidas ya implementadas previamente ${ }^{4,6}$.

Durante el año 2005, se realizó una nueva evaluación del resultado de la aplicación de estas medidas de prevención de TV del VIH utilizadas en el binomio madre-hijo en el período comprendido entre enero de 1998 y julio de 2005, cuyos resultados se presentan a continuación. Para ello se realizó seguimiento prospectivo de todos los hijos de madre seropositivas conocidas para VIH, incorporadas en protocolos de prevención, de acuerdo con la normativa establecida por el Comité Nacional de VIH/SIDA Pediátrico y el Instituto de Salud Pública, según la cual se realiza detección de ADN mediante la técnica de RPC, antigenemia y determinación de anticuerpos en las primeras 48 horas de vida del niño, entre los 15 y 30 días y a los 3 meses de edad ${ }^{1,10}$.

Este protocolo permite comprobar o descartar la infección por VIH en el hijo de madre seropositiva, ya a los 3 a 4 meses de edad. Un niño está infectado cuando dos exámenes de RPC resultan positivos y no infectado cuando dos exámenes de RPC resultan negativos.

Durante el período de estudio ingresaron a PPTV 401 mujeres embarazadas en todo el país, 53,4\% de ellas procedía de la Región Metropolitana (Tablas 1 y 2).

En $87,0 \%$ de los casos se usó TARV durante las tres etapas que contemplan los protocolos: embarazo, parto y las primeras seis semanas de vida del RN. En el resto no se cumplió con la administración de ellos

Tabla 2. Prevención de la transmisión vertical del VIH en Chile. Distribución casos en protocolos

\begin{tabular}{|lcc|}
\hline $\begin{array}{l}\text { Región } \\
\text { Administrativa }\end{array}$ & $\mathbf{n}$ en & protocolos \\
\hline RM & 214 & 53,4 \\
\hline I-II-III-IV-V & 108 & 26,9 \\
\hline VI-VII-VIII & 38 & 9,5 \\
\hline IX-X-XI-XII & 41 & 10,2 \\
\hline Total & 401 & 100 \\
\hline
\end{tabular}


durante alguna de estas etapas, generalmente, por pesquisa tardía de la infección en la madre (Tabla 3).

En relación con el manejo obstétrico, en $86,8 \%$ de los casos se cumplió con la indicación de cesárea electiva antes del trabajo de parto, en 7,2\% la cesárea se debió a alguna complicación obstétrica y en $6 \%$ la resolución del parto fue vaginal, por ingreso de la mujer gestante en trabajo de parto avanzado, o por desconocerse su condición de infectada. La recomendación de resolver el parto antes de cuatro horas de romperse las membranas, se cumplió en 374 casos $(93,9 \%)$

\begin{tabular}{|c|c|c|}
\hline Uso de TARV & n en protocolos & $\%$ \\
\hline Embarazo + Parto + RN & 349 & 87,0 \\
\hline Parto+RN & 33 & 8,2 \\
\hline RN & 13 & 3,3 \\
\hline Embarazo $+\mathrm{RN}$ & 6 & 1,5 \\
\hline Total & 401 & 100 \\
\hline
\end{tabular}

Tabla 4. Prevención de la TV del VIH, en Chile TARV usada en 401 binomios madre-hijo (1998-2000 y 2001-07/2005)

\begin{tabular}{lcccc} 
& \multicolumn{2}{c}{$\begin{array}{c}\mathbf{1 9 9 8 - 2 0 0 0} \\
\mathbf{n = 1 1 5}\end{array}$} & \multicolumn{2}{c|}{$\begin{array}{c}\mathbf{2 0 0 1 - 0 7 / 2 0 0 5} \\
\mathbf{n = 2 8 6}\end{array}$} \\
ARV & $\mathrm{n}$ & $\%$ & $\mathrm{n}$ & $\%$ \\
ZDV (ACTG-076) & 89 & 77,4 & 107 & 37,4 \\
Biterapia & 18 & 15,6 & 48 & 16,8 \\
Triterapia & 8 & 7,0 & 131 & 45,8 \\
\hline ZDV: zidovudina & & & & \\
\hline
\end{tabular}

Tabla 5. RN infectados con VIH, hijos de madres en PPTV*, Chile

\begin{tabular}{|lcc|}
\hline $\begin{array}{l}\text { Año de } \\
\text { nacimiento }\end{array}$ & $\begin{array}{c}\text { Binomios } \\
\text { madre/hijo }\end{array}$ & Hijos (+)s \\
1998 & 37 & 1 \\
1999 & 35 & 1 \\
2000 & 43 & 2 \\
2001 & 54 & - \\
2002 & 62 & 1 \\
2003 & 61 & 2 \\
2004 & 74 & 1 \\
2005 (a julio 31) & 35 & - \\
\hline Total & 401 & 8 \\
\hline * Protocolo para la prevención de la transmisión vertical
\end{tabular}

La TARV usada se modificó durante el período evaluado; en comienzo (1998-2000), 77,4\% recibió ZDV, de acuerdo con el protocolo PACTG 076 y en el resto se usó bi o triterapia, en mujeres incluidas en algún protocolo de investigación. Posteriormente, entre los años 2001 y julio 2005, el uso de ZDV sola se redujo a $37,4 \%$ de los casos, siendo reemplazada por triterapia en $45,8 \%$ (Tabla 4 ).

De las 401 hijos de estas madres seropositivas nacieron ocho niños infectados con el virus $(2,0 \%)$ (Tabla 5).

Un análisis de los ocho niños infectados reveló que en sólo dos de ellos se usó TARV durante las tres etapas: embarazo, parto y recién nacido; en uno de ellos se usó el protocolo PACTG 076 (ZDV) y en el otro triterapia. En cuatro casos se resolvió el parto por cesárea electiva antes del trabajo de parto. En uno se realizó cesárea por complicación obstétrica y en los otros tres el parto fue vaginal. Sólo en cinco de los casos el tiempo de membranas rotas fue menor a cuatro horas (Tabla 6).

Si bien se puede concluir que la utilización de PPTV durante los años de este estudio fue exitosa, debemos tener presente que ellos se refieren sólo a aquellas mujeres en las que se pesquisó la infección por VIH durante el embarazo o se conocía su condición de infectadas previamente y así tuvieron acceso a dichos protocolos. Sin embargo, durante los años de este estudio continuaron naciendo niños infectados con VIH, hijos de mujeres en las que no se conocía su condición de seropositividad ni se pesquisó durante el embarazo, por lo que no tuvieron acceso a PPTV. Es así que durante los años de este seguimiento, en el que sólo ocho niños de madres incorporadas a PPTV se infectaron, se pesquisaron 94 niños infectados hasta el 31 de julio de 2005. Se debe destacar que otros niños infectados aún no habían sido diagnosticados a la fecha de esta evaluación, ya que en algunos, el diagnóstico se realiza varios años después del nacimiento (Tabla 7).

Estos resultados reafirman que la medida fundamental para reducir los casos de infección por VIH en niños es su pesquisa universal en todas las mujeres durante el embarazo, de manera que accedan, en forma oportuna, a protocolos de prevención de la transmisión que han demostrado ser exitosos, más aún, si consideramos que en Chile el control prenatal es de $90 \%$ y la cobertura asistencial del parto es de 99,6\%.

En agosto de 2005, la Comisión Nacional del SIDA del Ministerio de Salud promulgó la nueva Norma de Prevención de la Transmisión Vertical del VIH, la que incorporó la oferta universal, con consejería previa, de la prueba de ELISA para VIH a todas las mujeres en su segundo control de embarazo y una prueba rápida a aquellas que llegan al parto sin haberse realizado este 


\begin{tabular}{|c|c|c|}
\hline \multicolumn{3}{|c|}{$\begin{array}{l}\text { Tabla 6. Medidas de prevención en niños } \\
\text { infectados que recibieron } \operatorname{PPTV}^{*}(\mathrm{n}: \mathbf{8})^{* *}\end{array}$} \\
\hline \multirow[t]{4}{*}{ Terapia anti-retroviral } & Embarazo, parto, $\mathrm{RN}^{* * *}$ & $2 * * *$ \\
\hline & Embarazo y $\mathrm{RN}$ & 1 \\
\hline & Intraparto y RN & 3 \\
\hline & Sólo RN & 2 \\
\hline \multirow[t]{3}{*}{ Parto } & Cesárea electiva & 4 \\
\hline & Cesárea obstétrica & 1 \\
\hline & Vaginal & 3 \\
\hline \multirow[t]{2}{*}{ Rotura de membranas } & $<4$ horas & 5 \\
\hline & $>4$ horas & 3 \\
\hline \multicolumn{3}{|c|}{$\begin{array}{l}\text { * Protocolo para la prevención de la transmisión vertical } \\
\text { ** } 8 \text { niños infectados con VIH de } 401 \text { binomios en PPTV } \\
\text { ** } 1 \text { caso recibió ZDV y uno triterapia }\end{array}$} \\
\hline
\end{tabular}

examen; normativa que deberá traducirse en una disminución de niños infectados con este virus, nacidos a partir del año $2006^{6,11}$.

\section{Resumen}

La identificación de diversos factores que inciden en el riesgo de la transmisión madre-hijo del virus de inmunodeficiencia humana (VIH), permitió diseñar estrategias dirigidas a disminuir su transmisión, entre ellas, medidas destinadas a disminuir la carga viral de la madre, disminuir la exposición del niño al VIH durante el parto y eliminar la exposición al mismo a través de la leche materna. Destaca la administración de antiretrovirales durante el embarazo, parto y en el recién nacido, inicialmente, como protocolo PACTG 076 que

\begin{tabular}{|lccc|}
\hline \multicolumn{2}{|c}{ Tabla 7. Hijos infectados de madres VIH (+), con } & $\mathbf{y}$ sin PPTV* \\
\hline Año nacimiento & $\begin{array}{c}\text { Binomios con } \\
\text { profilaxis }\end{array}$ & $\begin{array}{c}\text { Con profilaxis } \\
\text { Hijos infectados }\end{array}$ & $\begin{array}{c}\text { Sin profilaxis } \\
\text { Hijos infectados }\end{array}$ \\
\hline 1998 & 37 & 1 & 12 \\
1999 & 35 & 1 & 7 \\
2000 & 43 & 2 & 15 \\
2001 & 54 & - & 19 \\
\hline 2002 & 62 & 1 & 10 \\
\hline 2003 & 61 & 2 & 12 \\
\hline 2004 & 74 & 1 & 94 \\
\hline 2005 (a julio 31) & 35 & - & \\
\hline Total & 401 & & \\
\hline & & & \\
\hline
\end{tabular}

utilizaba zidovudina y, posteriormente, el uso de triterapia. De esta manera, en las madres incorporadas en protocolos de profilaxis de transmisión vertical (TV) del VIH se logró reducir la transmisión de este virus, inicialmente, a 9,5\% y en la última evaluación, realizada entre 1998 y julio 2005, a 2\%. Sin embargo, han continuado naciendo niños infectados hijos de madres en las que no se conocía su condición serológica, lo que reafirma que la medida fundamental para disminuir los casos de infección por VIH en niños, es la pesquisa universal de la infección en las mujeres embarazadas, de manera que accedan en forma oportuna a protocolos de profilaxis, lo que se espera lograr con la nueva norma de prevención de TV del VIH, promulgada en agosto de 2005, por la Comisión Nacional del SIDA del Ministerio de Salud.

\section{Referencias}

1.- Chávez A, Álvarez A M, Wu E. Transmisión vertical de la infección por virus de inmunodeficiencia humana: Impacto de la aplicación del protocolo ACTG 076 en Chile. Rev Chil Infect 2000; 17: 297-301.

2.- Chávez A, Wu E, Álvarez A M y Comité Nacional de SIDA Pediátrico. Infección por virus de inmunodeficiencia humana en pediatría: Situación en Chile. Rev Chil Infect 2000; 17: 302-6.

3.- Abarzúa F, Núñez F, Hubinont $\mathrm{C}$, Bernard $\mathrm{P}$, Yombi J C, Vandercam B. Infección por virus de inmunodeficiencia humana en el embarazo: Tratamiento anti-retroviral y vía del parto. Rev Chil Infect 2005; 22: $327-37$.

4.- Public Health Service Task Force. Recommendations for use of antiretroviral drugs in pregnant HIV-1-infected women. For maternal health and interventions to reduce perinatal HIV-1 transmission in the United States. October 12, 2006. http:// AIDSinfo.nih.gov (Accedido 6 julio 2007).

5.- Sperling R S, Shapiro D E, Coombs R W, Todd J A, Herman S A, Mc Sherry G D, et al Pediatric AIDS Clinical Trials Group Protocol 076 Study Group. Maternal viral load, zidovudine treatment, and the risk of transmission of human immunodeficiency virus type 1 from mother to infant. $\mathrm{N}$ Engl $\mathrm{J}$ Med, 1996; 335: 1621-9.

6.- Beltrán B C. ¿Es posible eliminar la transmisión madre-hijo del virus de inmunodeficiencia humana en Chile? Principales aspectos de la nueva Norma de Prevención de la Transmisión Vertical. Rev Chil Infect 2005; 22: 295-7.

7.- European collaborative study. Mother-to- child transmission of HIV infection in the era of highly active antiretroviral therapy. Clin Infect Dis 2005 40: 458-65.

8.- The International Perinatal HIV Group. The mode of delivery and the risk of vertical transmission of Human Immunodeficiency Virus type 1-a meta-analysis of 15 prospective cohort studies. N Engl J Med 1999; 340: 977-87.

9.- Connor E, Sperling R, Gelber R, Kiselev P, Scout G, O'Sullivan M, et al. Reduction of maternal-infant transmission of human immunodeficiency virus type 1 with zidovudine treatment. N Engl J Med 1994; 331: $1173-80$.

10.- Resolución exenta $\mathrm{N}^{\mathrm{o}} 371$. Ministerio de Salud. 02 Febrero, 2001.

11.- Ministerio de Salud. Guía clínica Síndrome de la Inmunodeficiencia Adquirida VIH/SIDA. MINSAL 2005. 